\title{
Effects of raw materials proportions on the sensory quality and antioxidant activities of apple/berry juice
}

\author{
Chang TAN ${ }^{1}$, Junxuan $\mathrm{LI}^{1}$, Chong XU1${ }^{1}$, Hongwei MENG ${ }^{1}$, Ying FENG ${ }^{1 \star}$ (D)
}

\begin{abstract}
In this study, response surface methodology (RSM) was used to study the effects of proportions of raw materials on the antioxidant activities of juices comprising mixtures of apples and berries (mixed juice; MJ). Among the four juices added, Acanthopanax sessiliflorus juice (ASJ) and its interaction with other juices had the most influence on the antioxidant activities. The MJ was optimized by blending 30\% apple juice (AJ), 5\% raspberry juice (RJ), 20\% BJ, and 20\% ASJ with $25 \%$ water. Sensory evaluation (SE) scores, scavenging rates of 2,2-diphenyl-1-picrylhydrazyl (DPPH), and 2,2'-azino-bis(3-ethylbenzothiazoline-6-sulfonic acid) (ABTS) in $\mathrm{MJ}$ were $89.67 \%, 64.80 \%$, and $73.30 \%$, respectively. The results of electronic tongue (e-Tongue) analysis show that the MJ reduced sourness, astringency and bitterness and improved sensory acceptance. Total phenolic content (TPC) and free radical scavenging activities in MJ was also increased compared with individual component juices. These findings should provide guidance for formulating new apple/berry compound juices.
\end{abstract}

Keywords: response surface methodology; berry juice; sensory property; antioxidant activity; electronic tongue.

Practical Application: Optimization of berry juice formula to improve the sensory quality and antioxidant activities.

\section{Introduction}

Various phytochemical constituents of berries exert antioxidant, anti-carcinogenic, vasodilatory and antimicrobial properties effects (Mullen et al., 2002; Paredes-López et al., 2010). The most significant health benefits of berries are attributed to phenolic compounds such as flavonoids, phenolic acids and anthocyanins (Paredes-López et al., 2010). However, some berries are rich in ellagic acid, tannin and other ingredients, which impart desirable flavors such as sour, astringent and bitter, and their individual processed products are not desirable by consumers, thus such berries have not been well investigated or developed.

Raspberries are an excellent source of phenols, and extracts include natural colorants and antioxidants (Espín et al., 2000). However, bright red raspberries and their products have high ellagic acid and ellagitannin content, which gives them a unique flavor that is not regarded by consumers as being particularly pleasant (Bobinaite et al., 2013). Blueberries and their products, such as juice and jam, are popular with consumers because of their good sensory evaluation and aromatic flavor. Blueberries are abundant in complex polyphenols with biological activities, among which, the content of anthocyanins is the highest (Cesa et al., 2017; Chen et al., 2015). However, the color of anthocyanins is greatly affected by $\mathrm{pH}$, and blueberry products on the market are mainly dark blue owing to a weakly acidic $\mathrm{pH}$, which might affect consumer choices to some extent.

Acanthopanax sessiliflorus (Rupr. et Maxim., A. sessiliflorus) seem is a new resource food and mainly used in traditional Chinese medicine as a sedative and as a treatment for rheumatism. Its extracts have received attention owing to having potential health benefits, such as hypolipidemic and anti-rotaviral properties (Bae et al., 2001). Flavonoids, triterpenoids, and coumarins are the main chemical constituents isolated from A. sessiliflorus (Chen et al., 2020; Lee et al., 2002). Because A. sessiliflorus has powerful physiological activities, it has potential value from the viewpoints of drug development and investigations into novel functional foods (Kim et al., 2011), but the development of A. sessiliflorus juice has not been investigated in detail.

Raspberry, blueberry and A. sessiliflorus are fruits rich in polyphenols with anti-oxidative properties. But the single products have specific defects, thus, mixing berry constituents with apple juice might result in new products with synergetic nutrients that could enhance the biological activities of the original individual raw materials. In addition, the sensory acceptability of compound juice by consumers might be improved by a pleasant taste. Response surface methodology (RSM) is often used to optimize process parameters, which has the characteristics of fewer experiments and higher precision. Curi et al. (2017) found that persimmon, orange and pineapple juice mixed using RSM has better sensory and nutritional characteristics than the isolated components and was attractive to consumers. Therefore, RSM is a good choice to optimize the proportion of mixed juice.

The objectives of this study were to create a novel mixed juice comprising apples, raspberries, blueberries and A. sessiliflorus fruit with better health benefits and sensory properties that would please consumers. RSM was used to investigate the effects of the proportions of raw materials required to produce a tasty, compound nutritional juice. The physicochemical properties, 
phenolic content, and antioxidant activities between the compound and individual component juices were compared, and gustatory properties were assessed using an electronic tongue. These findings should provide guidance for formulating new apple/berry compound juices, and help accelerate the utilization of berrys and apples resources.

\section{Materials and methods}

\subsection{Materials and reagents}

Apples, raspberries, blueberries and A. sessiliflorus fruits were purchased from local markets (Shenyang, Liaoning Province, China). Gallic acid, DPPH and ABTS were obtained from Solebo (Beijing, China). All other reagents were of analytical grade unless noted otherwise.

\subsection{Preparation of mixed juices}

Cleaned, peeled, and sliced apples were immersed in $0.3 \% \mathrm{Na}_{2} \mathrm{SO}_{3}$ for $1 \mathrm{~h}$ to prevent oxidative browning, and then thoroughly rinsed with water. The apples were squeezed using a domestic press to prepare cloudy apple juice (AJ). Raspberries and blueberries were pressed into juices (RJ and BJ, respectively), and A. sessiliflorus fruits rehydrated with water at $80^{\circ} \mathrm{C}$ at a ratio of $1: 10(\mathrm{~g} / \mathrm{mL})$ for $40 \mathrm{~min}$ were pressed to yield juice (ASJ). Mixed juices (MJ) were obtained by blending AJ, RJ, BJ and ASJ, then adding water to $200 \mathrm{~g}$.

\subsection{RSM design}

Based on single factor tests (data not shown), a four-factor and three-level Box-Behnken design (BBD) were assessed and 29 individual run points were analyzed to investigate the influence of the proportions of raw materials and optimize the formula of the mixed juice. The added $\mathrm{AJ}\left(\mathrm{X}_{1}\right), \mathrm{RJ}\left(\mathrm{X}_{2}\right), \mathrm{BJ}\left(\mathrm{X}_{3}\right)$ and ASJ $\left(\mathrm{X}_{4}\right)$ were independent variables, $\mathrm{SE}\left(\mathrm{Y}_{1}\right), \mathrm{DPPH}\left(\mathrm{Y}_{2}\right)$ and ABTS $\left(\mathrm{Y}_{3}\right)$ radical scavenging abilities served as response values (Table 1).

\subsection{Sensory Evaluation (SE)}

Twenty trained assessors selected from among the students of Shenyang Agricultural University conducted an SE of the juice samples, and the selection basis and evaluation environment refer to the requirements of Nascimento et al. (2020). The attributes of color, flavor, taste, appearance and overall acceptability were evaluated using a hedonic scale from 1 (extreme dislike)

Table 1. Independent variable values and their corresponding proportions used in RSM.

\begin{tabular}{ccccc}
\hline \multirow{2}{*}{$\begin{array}{c}\text { Independent } \\
\text { variables }\end{array}$} & Symbol & \multicolumn{3}{c}{ Coded variables levels } \\
\cline { 3 - 5 } AJ (\%) & $\mathrm{X}_{1}$ & -1 & 0 & 1 \\
RJ (\%) & $\mathrm{X}_{2}$ & 2.5 & 30 & 35 \\
BJ (\%) & $\mathrm{X}_{3}$ & 15 & 20 & 7.5 \\
ASJ (\%) & $\mathrm{X}_{4}$ & 15 & 20 & 25 \\
\hline
\end{tabular}

$\mathrm{AJ}=$ apple juice; $\mathrm{RJ}$ = raspberry juice; $\mathrm{BJ}=$ blueberry juice; $\mathrm{ASJ}=\mathrm{A}$. sessiliflorus juice. to 9 (extreme like) and recorded as described by Liu et al. (2016) with some modifications.

\subsection{Physicochemical properties}

Total soluble solids (TSS) in MJ were determined using a refractometer (Suwei, Guangzhou, China), and the $\mathrm{pH}$ was determined using a PB-10 digital pH meter (Sartorius AG., Göttingen, Germany). Total titratable acidity (TTA as citric acid) and reducing sugars (RS) were determined according to the Association of Official Analytical Chemists (1998). Physicochemical properties were assessed at ambient temperature $\left(25^{\circ} \mathrm{C} \pm 2{ }^{\circ} \mathrm{C}\right)$.

\subsection{Radical scavenging activities and polyphenols}

\section{Preparation of juice samples}

Juice samples were prepared as described by Bahukhandi et al. (2018) with modifications. Fruit juice ( $1 \mathrm{~g})$ in $20 \mathrm{~mL}$ methanol $(80 \%, \mathrm{v} / \mathrm{v})$ containing $0.1 \%(\mathrm{v} / \mathrm{v})$ hydrochloric acid at $50^{\circ} \mathrm{C}$ were extracted by ultrasonication at $700 \mathrm{~W}$ (KQ-700DV, Kunshan Ultrasonic Instrument Co. Ltd., Jiangsu, China) for $30 \mathrm{~min}$, then separated by centrifugation at $10000 \times g$ for $20 \mathrm{~min}$ at $4{ }^{\circ} \mathrm{C}$ (CR21G refrigerated centrifuge Hitachi Co. Ltd., Tokyo, Japan). The supernatant was decanted, diluted to a final volume of $25 \mathrm{~mL}$, sealed and stored at $-20^{\circ} \mathrm{C}$ until analysis.

\section{DPPH radical scavenging activity assays}

The DPPH radical scavenging activity was determined as described by Brand-Williams et al. (1995) with slightly modifications. Briefly, juice samples $(50 \mu \mathrm{L})$ were incubated in darkness with $950 \mu \mathrm{L}$ of $0.1 \mathrm{mM} \mathrm{DPPH}$ in $95 \%$ ethanol for $30 \mathrm{~min}$ at room temperature. The absorbance of the sample $\left(\mathrm{A}_{1}\right)$ was measured at $517 \mathrm{~nm}$ using a Spectramax M3 microplate reader with SoftMax Pro software (Molecular Devices LLC., Sunnyvale, CA, USA). The DPPH scavenging activity was calculated as follows (Equation 1):

$I_{D P P H}(\%)=\left[A_{0}-\left(A_{1}-A_{2}\right)\right] / A_{0} \times 100$

where $A_{0}$ is the absorbance of control group (sample solution replaced with extraction solvent), and $\mathrm{A}_{2}$ is the absorbance of sample blank (DPPH solution replaced by $95 \%$ ethanol).

\section{ABTS radical scavenging activity assays}

The ABTS radical scavenging activity was measured as described by Lee et al. (2003) with some modification. An ABTS cation stock solution was prepared by reacting $40 \mu \mathrm{L}$ of $7.4 \mathrm{mM}$ ABTS with $40 \mu \mathrm{L}$ of $2.6 \mathrm{mM}$ potassium persulfate for 16 hours. The ABTS cation stock solution was diluted with phosphate buffer ( $\mathrm{pH} 7.0$ ) to $0.7 \pm 0.05$, and absorbance was determined at $734 \mathrm{~nm}$. Juice samples $(10 \mu \mathrm{L})$ in 96 -well plates were incubated with $200 \mu \mathrm{L}$ of diluted ABTS for 6 min incubation. Absorbance of the sample $\left(\mathrm{A}_{1}\right)$ was determined at $734 \mathrm{~nm}$ in the microplate reader. The ABTS scavenging activity $\left(\mathrm{I}_{\mathrm{ABTS}}\right)$ was calculated as follows (Equation 2):

$I_{A B T S}(\%)=\left[A_{0}-\left(A_{1}-A_{2}\right)\right] / A_{0} \times 100$ 
where $A_{0}$ is the absorbance of the control (sample solution replaced with extraction solvent), and $\mathrm{A}_{2}$ is the absorbance of the blank (ABTS solution was replaced by phosphate buffer).

\subsection{Determination of total phenolic content}

Total phenolic content (TPC) of juices was assayed using the Folin-Ciocalteau method as described by Singleton \& Rossi (1965). Briefly, juice samples $(0.2 \mathrm{~mL})$ in $5.5 \mathrm{~mL}$ of distilled water were reacted with $0.5 \mathrm{~mL}$ of $1 \mathrm{M}$ Folin-Ciocalteau reagent for $1 \mathrm{~min}$, followed by $2 \mathrm{~mL}$ of $20 \% \mathrm{Na}_{2} \mathrm{CO}_{3}$ at room temperature for 2 hours in darkness. Absorbance was then measured at $760 \mathrm{~nm}$ by spectrophotometry. Results are expressed as gallic acid equivalents (GAE) based on a standard curve of gallic acid (mg GAE/100 g juice weight [JW]).

\subsection{Gustatory analysis}

The sensory response value of juice samples was measured as described by Laureati et al. (2010) with some modification. Juice samples $(\sim 35 \mathrm{~mL})$ in specific measuring cups were placed on the automatic sampler of a SA-402B electronic tongue (Intelligent Sensor Technology Co., Kanagawa, Japan) equipped for $30 \mathrm{~s}$ and rinsed with distilled water between measurements to reach a steady signal state. Data were collected by alternating between a calibrated standard and quadruplicate juice samples.

\subsection{Statistical analysis}

Data are presented as means \pm standard deviation. The RSM data were assessed by analysis of variance (ANOVA) using Design Expert 8.0.6 software. Other data were analyzed using Origin 2019b and SPSS 7.0 software (SPSS Inc., Chicago, IL, USA). Mean values were considered significantly different at $p<0.05$ and more significantly different at $p<0.01$. All analyses were conducted at least in triplicate.

\section{Results and discussion}

\subsection{Fitting the model}

Table 2 shows the response variables and values of 29 runs. The fitness of the polynomial equation to the responses was estimated using and the statistical significance of the models was examined using ANOVA. Each group of models reached $p<0.01$, and the lack of fit was not significant $(p>0.05)$, reflecting that the regression models adequately explained the relationships between the independent variables and responses. The $\mathrm{R}^{2}$ (determination coefficients) values of the models for

Table 2. Box-Behnken design (BBD) for the independent variables and corresponding response values.

\begin{tabular}{|c|c|c|c|c|c|c|c|}
\hline Runs & $\mathrm{AJ}(\%)\left(\mathrm{X}_{1}\right)$ & $\mathrm{RJ}(\%)\left(\mathrm{X}_{2}\right)$ & $\mathrm{BJ}(\%)\left(\mathrm{X}_{3}\right)$ & $\mathrm{ASJ}(\%)\left(\mathrm{X}_{4}\right)$ & $\mathrm{SE}\left(\mathrm{Y}_{1}\right)$ & $\mathrm{DPPH}(\%)\left(\mathrm{Y}_{2}\right)$ & $\operatorname{ABTS}(\%)\left(\mathrm{Y}_{3}\right)$ \\
\hline 1 & $-1(25)$ & $-1(2.5)$ & $0(20)$ & $0(20)$ & 7.02 & 49.97 & 44.75 \\
\hline 2 & $1(35)$ & $-1(2.5)$ & $0(20)$ & $0(20)$ & 6.93 & 58.87 & 41.67 \\
\hline 3 & $-1(25)$ & $1(7.5)$ & $0(20)$ & $0(20)$ & 7.02 & 51.36 & 43.69 \\
\hline 4 & $1(35)$ & $1(7.5)$ & $0(20)$ & $0(20)$ & 7.20 & 58.39 & 42.75 \\
\hline 5 & $0(30)$ & $0(5)$ & $-1(15)$ & $-1(15)$ & 6.84 & 54.55 & 43.54 \\
\hline 6 & $0(30)$ & $0(5)$ & $1(25)$ & $-1(15)$ & 7.20 & 42.23 & 46.40 \\
\hline 7 & $0(30)$ & $0(5)$ & $-1(15)$ & $1(25)$ & 7.47 & 48.11 & 51.25 \\
\hline 8 & $0(30)$ & $0(5)$ & $1(25)$ & $1(25)$ & 7.29 & 54.67 & 53.88 \\
\hline 9 & $-1(25)$ & $0(5)$ & $0(20)$ & $-1(15)$ & 7.02 & 46.08 & 44.94 \\
\hline 10 & $1(35)$ & $0(5)$ & $0(20)$ & $-1(15)$ & 7.65 & 57.65 & 54.61 \\
\hline 11 & $-1(25)$ & $0(5)$ & $0(20)$ & $1(25)$ & 7.74 & 52.36 & 48.50 \\
\hline 12 & $1(35)$ & $0(5)$ & $0(20)$ & $1(25)$ & 6.75 & 59.48 & 41.17 \\
\hline 13 & $0(30)$ & $-1(2.5)$ & $-1(15)$ & $0(20)$ & 7.29 & 57.71 & 41.77 \\
\hline 14 & $0(30)$ & $1(7.5)$ & $-1(15)$ & $0(20)$ & 7.38 & 56.27 & 50.49 \\
\hline 15 & $0(30)$ & $-1(2.5)$ & $1(25)$ & $0(20)$ & 7.56 & 51.64 & 51.33 \\
\hline 16 & $0(30)$ & $1(7.5)$ & $1(25)$ & $0(20)$ & 7.20 & 53.00 & 48.44 \\
\hline 17 & $-1(25)$ & $0(5)$ & $-1(15)$ & $0(20)$ & 7.29 & 53.91 & 50.72 \\
\hline 18 & $1(35)$ & $0(5)$ & $-1(15)$ & $0(20)$ & 7.11 & 61.35 & 42.10 \\
\hline 19 & $-1(25)$ & $0(5)$ & $1(25)$ & $0(20)$ & 7.29 & 48.56 & 48.18 \\
\hline 20 & $1(35)$ & $0(5)$ & $1(25)$ & $0(20)$ & 7.47 & 62.53 & 52.44 \\
\hline 21 & $0(30)$ & $-1(2.5)$ & $0(20)$ & $-1(15)$ & 6.66 & 47.07 & 38.28 \\
\hline 22 & $0(30)$ & $1(7.5)$ & $0(20)$ & $-1(15)$ & 7.92 & 48.08 & 56.21 \\
\hline 23 & $0(30)$ & $-1(2.5)$ & $0(20)$ & $1(25)$ & 7.83 & 52.74 & 50.72 \\
\hline 24 & $0(30)$ & $1(7.5)$ & $0(20)$ & $1(25)$ & 6.84 & 50.78 & 43.53 \\
\hline 25 & $0(30)$ & $0(5)$ & $0(20)$ & $0(20)$ & 8.10 & 64.84 & 78.97 \\
\hline 26 & $0(30)$ & $0(5)$ & $0(20)$ & $0(20)$ & 8.37 & 65.23 & 79.59 \\
\hline 27 & $0(30)$ & $0(5)$ & $0(20)$ & $0(20)$ & 8.46 & 62.14 & 76.90 \\
\hline 28 & $0(30)$ & $0(5)$ & $0(20)$ & $0(20)$ & 8.19 & 69.31 & 73.36 \\
\hline 29 & $0(30)$ & $0(5)$ & $0(20)$ & $0(20)$ & 8.28 & 66.00 & 70.09 \\
\hline
\end{tabular}

$\mathrm{AJ}=$ apple juice; $\mathrm{RJ}=$ raspberry juice; $\mathrm{BJ}=$ blueberry juice; $\mathrm{ASJ}=\mathrm{A}$. sessiliflorus juice; $\mathrm{SE}=$ sensory evaluation. 
the recovery of responses were close to 1 , indicating that the models correlated reasonably well with the experimental data (Chen et al., 2018).

\subsection{Influence of raw juices on radical scavenging activity of compound juice}

\section{Sensory Evaluation (SE)}

The ANOVA result shows that the quadratic $\mathrm{X}_{1}^{2}, \mathrm{X}_{2}^{2}, \mathrm{X}_{3}^{2}$ and $\mathrm{X}_{4}{ }^{2}$ and interactive $\mathrm{X}_{1} \mathrm{X}_{4}, \mathrm{X}_{2} \mathrm{X}_{4}$ significantly affected $\mathrm{SE}(p<0.01)$, whereas all other terms were insignificant $(p>0.05)$. The fitted quadratic regression equation for $\mathrm{SE}\left(\mathrm{Y}_{1}\right)$ was estimated by RSM as follows (Equation 3):

$$
\begin{aligned}
& Y_{1}(\mathrm{SE})=8.28-0.015 \mathrm{X}_{1}+0.023 X_{2}+0.045 \mathrm{X}_{3}+0.052 \mathrm{X}_{4}+0.067 \mathrm{X}_{1} X_{2}+0.11 \mathrm{X}_{1} X_{3}- \\
& 0.41 \mathrm{X}_{1} X_{4}-0.11 \mathrm{X}_{2} X_{3}-0.56 \mathrm{X}_{2} X_{4}-0.13 \mathrm{X}_{3} X_{4}-0.59 \mathrm{X}_{1}^{2}-0.53 \mathrm{X}_{2}^{2}-0.47 \mathrm{X}_{3}^{2}-0.48 \mathrm{X}_{4}^{2}
\end{aligned}
$$

The 3-dimensional (3D) graphs of the variables in Figure 1 show the interactive effects in RSM. Figure $1 \mathrm{a}$ and $1 \mathrm{~b}$ correspond to $\mathrm{SE}$ and demonstrate the interactive effects of $\mathrm{X}_{1} \mathrm{X}_{4}$ and $\mathrm{X}_{2} \mathrm{X}_{4}$, both of which are in downward opening directions. This indicated that the response values have maxima. The sensory score of the blended juices was affected by adding ASJ, whereas added BJ and other juices did not interact. This outcome might be owing to the better sensory acceptability of BJ; its aromatic compounds, low acidity and high sweetness caused less fluctuation in the SE of MJ (Vázquez-Araujo et al., 2010).

\section{$D P P H$ radical scavenging activity}

The ANOVA results show a significant effect of added BJ $\left(\mathrm{X}_{3}\right)$ on the DPPH- scavenging activity of mixed juice $(\mathrm{P}<0.05)$, and a highly significant effect of added ASJ $\left(\mathrm{X}_{4}\right)(\mathrm{P}<0.01)$. The fitted quadratic regression equation for DPPH radical scavenging activity $\left(\mathrm{Y}_{2}\right)$ estimated by RSM was as follows (Equation 4):

$$
\begin{aligned}
& Y_{2}(\%)=65.50+4.67 \mathrm{X}_{1}-0.01 X_{2}-1.61 \mathrm{X}_{3}+1.87 \mathrm{X}_{4}-0.47 \mathrm{X}_{1} X_{2}+1.63 \mathrm{X}_{1} X_{3}- \\
& 1.11 \mathrm{X}_{1} X_{4}+0.70 \mathrm{X}_{2} X_{3}-0.74 \mathrm{X}_{2} X_{4}+4.72 \mathrm{X}_{3} X_{4}-3.41 \mathrm{X}_{1}^{2}-6.49 \mathrm{X}_{2}^{2}-5.41 \mathrm{X}_{3}^{2}-9.25 \mathrm{X}_{4}^{2}
\end{aligned}
$$

The $3 \mathrm{D}$ graph of the interaction between added BJ and ASJ (Figure 1c) shows that as the amount of added ASJ increased, the DPPH - scavenging activity initially increased, then decreased. As the amount of added BJ increased, DPPH- scavenging activity slowly increased, then rapidly decreased.

\section{ABTS radical scavenging activity}

The ANOVA shows that the linear term had no significant effect on $\mathrm{ABTS}^{+}$- scavenging activity. In contrast, the interaction term $\mathrm{X}_{2} \mathrm{X}_{4}$ had significant effects on the $\mathrm{ABTS}^{+} \cdot$ scavenging activity of mixed juice $(\mathrm{P}<0.01)$, followed by $\mathrm{X}_{1} \mathrm{X}_{4}(\mathrm{P}<0.05)$. The fitted quadratic regression equation for ABTS radical scavenging activity $\left(\mathrm{Y}_{3}\right)$ estimated by RSM was as follows (Equation 5):

$Y_{3}(\%)=75.78-0.50 \mathrm{X}_{1}+1.38 X_{2}+1.73 \mathrm{X}_{3}+0.42 \mathrm{X}_{4}+0.53 \mathrm{X}_{1} X_{2}+3.22 \mathrm{X}_{1} X_{3}-$

$4.25 \mathrm{X}_{1} X_{4}-2.90 \mathrm{X}_{2} X_{3}-6.28 \mathrm{X}_{2} X_{4}-0.057 \mathrm{X}_{3} X_{4}-15.59 \mathrm{X}_{1}^{2}-15.83 \mathrm{X}_{2}^{2}-12.46 \mathrm{X}_{3}^{2}-13.40 \mathrm{X}_{4}^{2}$

Figure $1 \mathrm{~d}$ and e shows that the $\mathrm{ABTS}^{+} \cdot$ scavenging activity initially increased, and then decreased when more AJ and RJ were added. While the variation amplitude was higher and the trend was more obvious when less ASJ was added. Berries have powerful antioxidant ability owing to their abundant anthocyanin compounds. Bagchi et al. (2004) developed a synergistic formula of six combined berry extracts that had better antioxidant and anti-angiogenesis properties than any one type of berry. This indicated that antioxidant effects will become synergistic after appropriate compounding. However, synergistic effects are a

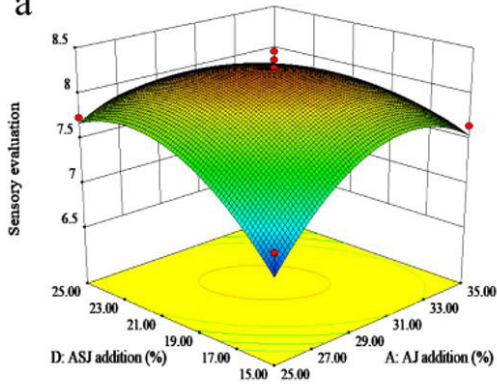

b

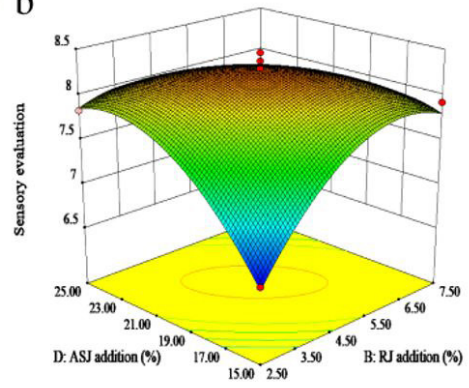

C

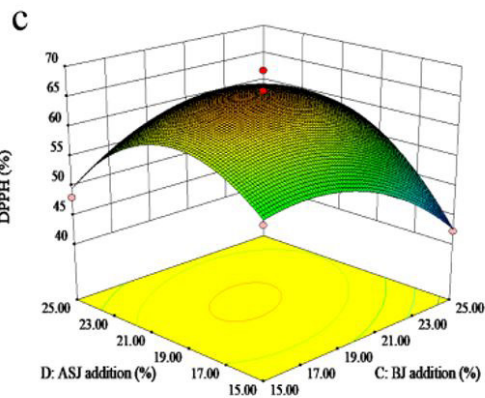

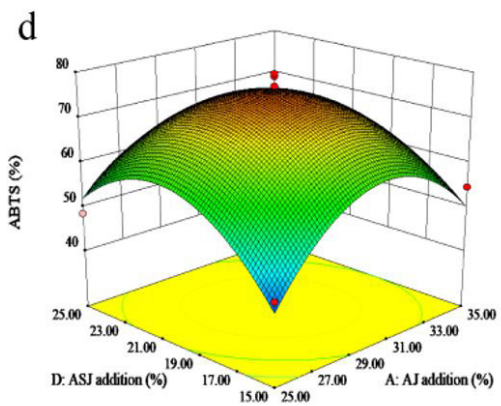

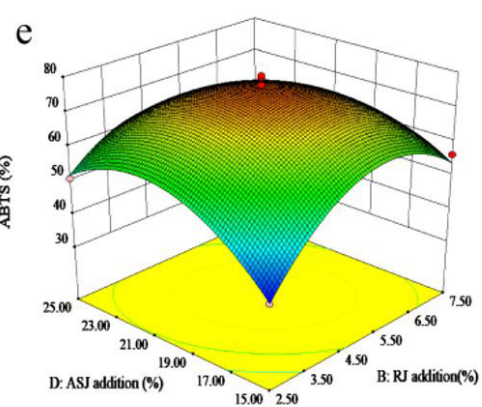

Figure 1. Interactive effects of added variables on sensory evaluation (a, b), DPPH (c) and ABTS (d, e) radical scavenging activity. 
affected by concentration and other factors. Adding too much of a particular juice might reduce antioxidant effects.

\subsection{Verification of response surface test model}

After optimization of RSM, the MJ formulations with the optimal SE score, DPPH* and $\mathrm{ABTS}^{+} \cdot$ scavenging activities were obtained. The experimental findings and technological parameters indicated that the optimal amounts of added AJ, RJ, BJ and ASJ were $30 \%, 5 \%, 20 \%$ and $20 \%$, respectively. The SE score, $\mathrm{DPPH}$ - and $\mathrm{ABTS}^{+}$- scavenging activities were $8.07 \pm 0.19$, $64.80 \% \pm 2.26 \%$ and $73.30 \% \pm 2.35 \%$, which were reached $97.43 \%, 96.52 \%$ and $96.61 \%$ of predicted values, respectively.

\subsection{Comparison of various indicators between samples of individual component and $M J$}

Process parameters optimized through RSM were selected to prepare MJ. The physicochemical indexes, phenolic compounds content and radical scavenging activities of mixed and component juices were measured (Table 3 ).

\section{Determination of physicochemical properties in juices}

As seen in Table 3, TSS and RS of AJ were the highest, reaching $11.7^{\circ}$ Brix and $7.49 \%$, respectively, whereas the berry juices lacked TSS and RS, and ASJ was the lowest at $4.0^{\circ}$ Brix and $2.11 \%$, respectively. In addition, the TTA of ASJ was also the lowest among individual juices, and the $\mathrm{pH}$ was the highest and weakly acidic, which might have reduced the microbiological shelf life of ASJ compared with juices with a lower $\mathrm{pH}$. Raspberry juice had the highest TTA, but the lower RS content, which resulted in the lowest $\mathrm{pH}$. Although a low $\mathrm{pH}$ is beneficial to shelf life, consumers prefer juice with a high maturity index and low acidity (Vázquez-Araujo et al., 2010), which could explain why RJ has less sensory acceptance.

The TSS and RS of the MJ were $5.6^{\circ}$ Brix and 3.75\%, which were both higher than ASJ. The TTA of MJ was significantly higher than that of ASJ, and the $\mathrm{pH}$ was lower than that of ASJ $(p<0.05)$. The increase in TTA and the decrease in $\mathrm{pH}$ were because of the added RJ and BJ, which improved the acidity of the mixed juice and the added sugar, which rendered the acidity acceptable. These changes in TTA and $\mathrm{pH}$ are similar to the findings of Grobelna et al. (2019) who prepared a mixed juice comprising blue honeysuckle berry and apple juices.

\section{Determination of phenolic compounds content in juices}

Table 3 shows the phenolic compounds in five juices before and after mixing. The TPC of ASJ was the highest among the juices, namely $123.47 \mathrm{mg} \mathrm{GAE}$ per $100 \mathrm{~g} \mathrm{JW}(p<0.05)$. The TPC was significantly higher in $\mathrm{MJ}$ than in $\mathrm{AJ}$, RJ and $\mathrm{BJ}(p<0.05)$, indicating that the added ASJ increased the phenol content in the original individual fruit juices.

\section{Determination of radical scavenging rate in juices}

Table 3 indicates the radical scavenging rates of the juices. The ABTS free radical scavenging activities of $\mathrm{MJ}$ were significantly higher than those of AJ and BJ ( $p<0.05)$. The ability of MJ to scavenge DPPH was also significantly higher than that of AJ, RJ and BJ, respectively $(p<0.05)$. These results showed that mixed juice could improve the radical scavenging activity compared with individual fruit juices.

\subsection{Electronic tongue (e-Tongue) results and analysis of mixed juices}

\section{E-Tongue radar plot}

The radar plot in Figure 2a displays significantly higher sourness for BJ than other juices $(p<0.05)$, followed by RJ, which is owing to the high content of TTA in raspberries $(0.17 \%)$ and blueberries $(0.15 \%)$. While BJ also had the highest sweetness value ( $p<0.05)$ owing to a great amount $(5.89 \%)$ of RS in blueberries, the overall flavor of BJ can be balanced. In contrast, the sweetness value was significantly lower for $\mathrm{RJ}$ than the other juices $(p<0.05)$, and its 5.15\% RS content resulted in RJ having an overall sour taste. Saltiness was the highest for RJ and lowest for $\mathrm{BJ}$ ( $p<0.05$ for both), and astringency was similarly the lowest in both $(p>0.05)$.

A. sessiliflorus is rich in terpenoids (Jiang et al., 2006; Yang et al., 2009), most of which taste bitter. Thus, ASJ had the highest score for bitterness $(p<0.05)$, but also had the highest score for umami $(p<0.05)$. The astringency of AJ was the highest $(p<0.05)$, because of higher tannin content (Sanoner et al., 1999), but sourness was lower. The flavors of the AJ were adjusted well after blending. The bitterness value of the mixed juice was significantly lower than that of ASJ, the acid value was significantly lower than that of $\mathrm{BJ}$ and $\mathrm{RJ}$, and astringency was significantly lower than that of AJ.

Table 3. Comparison of physicochemical properties, phenolic content, and radical scavenging activity between individual juice and mixed juices.

\begin{tabular}{|c|c|c|c|c|c|c|c|}
\hline \multirow{2}{*}{ Type of juice } & \multicolumn{4}{|c|}{ Physicochemical properties } & \multicolumn{2}{|c|}{ Radical scavenging activity } & \multirow{2}{*}{$\begin{array}{c}\text { TPC } \\
(\mathrm{mg} \mathrm{GAE} / 100 \mathrm{~g} \mathrm{JW})\end{array}$} \\
\hline & TSS ( ${ }^{\circ}$ Brix $)$ & TTA (\%) & RS (\%) & $\mathrm{pH}$ & DPPH (\%) & ABTS (\%) & \\
\hline AJ & $11.7 \pm 0.10 \mathrm{a}$ & $0.14 \pm 0.071 \mathrm{c}$ & $7.49 \pm 0.0015 \mathrm{a}$ & $3.4 \pm 0.10 \mathrm{~d}$ & $52.09 \pm 0.34 \mathrm{~d}$ & $62.15 \pm 0.20 c$ & $33.73 \pm 0.35 \mathrm{e}$ \\
\hline $\mathrm{RJ}$ & $7.2 \pm 0.10 c$ & $0.17 \pm 0.039 \mathrm{a}$ & $5.15 \pm 0.0063 c$ & $3.2 \pm 0.062 c$ & $61.69 \pm 0.14 b$ & $85.55 \pm 0.78 \mathrm{a}$ & $48.73 \pm 0.076 \mathrm{~d}$ \\
\hline BJ & $8.4 \pm 0.067 b$ & $0.15 \pm 0.0096 b$ & $5.89 \pm 0.0047 b$ & $3.4 \pm 0.055 c$ & $58.28 \pm 0.10 c$ & $64.28 \pm 0.41 c$ & $54.86 \pm 0.17 c$ \\
\hline ASJ & $4.0 \pm 0.10 \mathrm{e}$ & $0.084 \pm 0.011 \mathrm{~d}$ & $2.11 \pm 0.0015 \mathrm{e}$ & $5.6 \pm 0.033 a$ & $68.59 \pm 0.12 \mathrm{a}$ & $85.04 \pm 0.30 \mathrm{a}$ & $123.47 \pm 0.081 \mathrm{a}$ \\
\hline MJ & $5.6 \pm 0.55 \mathrm{~d}$ & $0.14 \pm 0.025 c$ & $3.75 \pm 0.0055 \mathrm{~d}$ & $3.5 \pm 0.062 b$ & $67.34 \pm 0.94 \mathrm{a}$ & $75.91 \pm 0.22 b$ & $75.29 \pm 0.50 \mathrm{~b}$ \\
\hline
\end{tabular}

$\mathrm{AJ}=$ apple juice; $\mathrm{RJ}=$ raspberry juice; $\mathrm{BJ}=$ blueberry juice; $\mathrm{ASJ}=$ A sessiliflorus juice; $\mathrm{MJ}=$ mixed juice; $\mathrm{TSS}=$ total soluble solids; $\mathrm{TTA}=$ total titratable acidity; $\mathrm{RS}=$ reducing sugar;

TPC $=$ total phenolic content. Different letters in the same column showed significant results $(\mathrm{p}<0.05)$. 

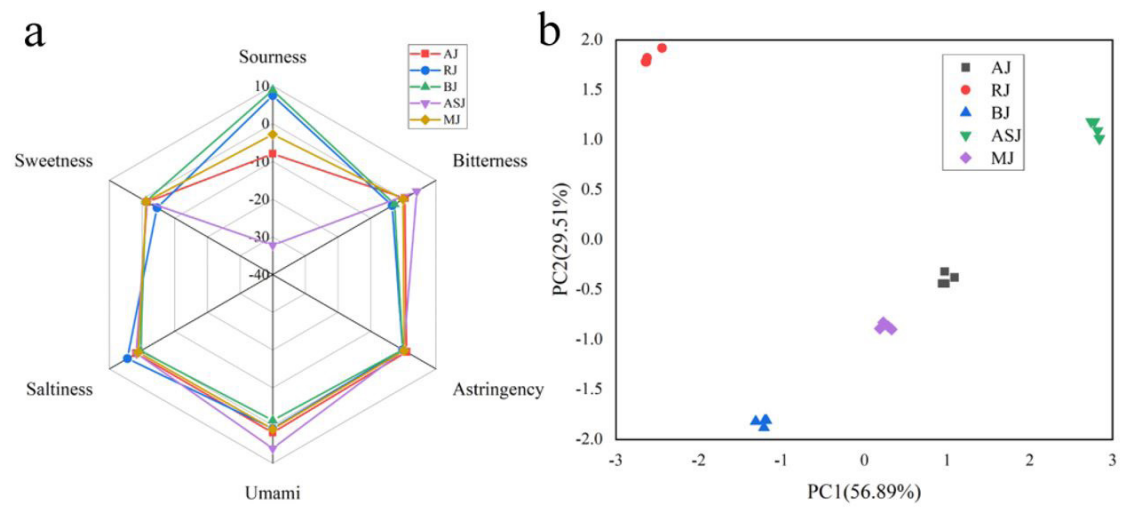

Figure 2. Radar (a) and PCA (b) plots of juices and sensor response data obtained by e-Tongue. AJ = apple juice; RJ = raspberry juice; $\mathrm{BJ}=$ blueberry juice; ASJ = A. sessiliflorus juice; $\mathrm{MJ}=$ mixed juice.

\section{Principal Component Analysis (PCA) of e-Tongue}

An evaluation of the ability of the e-Tongue to distinguish juices using PCA of a merged dataset (Figure 2b), showed that all five juices had good repeatability. Two principal components were obtained from the juice flavor, which explained 56.89\% and $29.51 \%$ of the captured information. Figure $2 b$ show clearly separated clusters corresponding to different single juice varieties, indicating that the PCA clearly distinguished the single juice samples (Haddi et al., 2014). The clusters for MJ and AJ were more concentrated, and they are located in the center of the figure, especially MJ. This phenomenon indicated that the mixed juice can efficiently neutralize the flavors of the four component juices, which further confirmed the results of the radar plot.

\section{Conclusions}

In this work, RSM was used to optimize mixed juices formula. The optimal conditions comprised $30 \%$ apple juice, $5 \%$ raspberry juice, $20 \%$ blueberry juice, and 20\% A. sessiliflorus juice. Sensory evaluation, DPPH and ABTS radical scavenging activities of the mixed juices reached the highest level. Compared with individual component juices, the mixed juices had an increased abundance of phenolic compounds and antioxidant activities. The flavors of the mixed juices were adjusted with lower sourness than blueberry and raspberry juice, lower bitterness than A. sessiliflorus juice, and lower astringency than apple juice. Therefore, this study developed a new apple-berry juice with good sensory acceptance and high antioxidant activity that also provides a theoretical basis for the production of functional beverages.

\section{Acknowledgements}

This work was supported by Shenyang Science and Technology Bureau (double hundred, grant number Z18-3-018).

\section{References}

Association of Official Analytical Chemists - AOAC. (1998). Official methods of analysis of AOAC International (16th ed., Method 945.66). Gaithersburg: AOAC. http://dx.doi.org/10.1002/0471740039.vec0284.
Bae, E. A., Yook, C. S., Oh, O. J., Chang, S. Y., Nohara, T., \& Kim, D. H. (2001). Metabolism of chiisanoside from Acanthopanax divaricatus var. albeofructus by human intestinal bacteria and its relation to some biological activities. Biological \& Pharmaceutical Bulletin, 24(5), 582-585. http://dx.doi.org/10.1248/bpb.24.582. PMid:11379786.

Bagchi, D., Sen, C. K., Bagchi, M., \& Atalay, M. (2004). Anti-angiogenic, antioxidant, and anti-carcinogenic properties of a novel anthocyaninrich berry extract formula. Biochemistry. Biokhimiia, 69(1), 75-80, 1, 75. http://dx.doi.org/10.1023/B:BIRY.0000016355.19999.93. PMid:14972022.

Bahukhandi, A., Dhyani, P., Bhatt, I. D., \& Rawal, R. S. (2018). Variation in polyphenolics and antioxidant activity of traditional apple cultivars from West Himalaya, Uttarakhand. Horticultural Plant Journal, 4(4), 151-157. http://dx.doi.org/10.1016/j.hpj.2018.05.001.

Bobinaite, R., Viškelis, P., Šarkinas, A., \& Venskutonis, P. R. (2013). Phytochemical composition, antioxidant and antimicrobial properties of raspberry fruit, pulp, and marc extracts. CYTA: Journal of Food, 11(4), 334-342. http://dx.doi.org/10.1080/19476337.2013.766265.

Brand-Williams, W., Cuvelier, M. E., \& Berset, C. (1995). Use of a free radical method to evaluate antioxidant activity. LebensmittelWissenschaft + Technologie, 28(1), 25-30. http://dx.doi.org/10.1016/ S0023-6438(95)80008-5.

Cesa, S., Carradori, S., Bellagamba, G., Locatelli, M., Casadei, M. A., Masci, A., \& Paolicelli, P. (2017). Evaluation of processing effects on anthocyanin content and colour modifications of blueberry (Vaccinium spp.) extracts: Comparison between HPLC-DAD and CIELAB analyses. Food Chemistry, 232, 114-123. http://dx.doi. org/10.1016/j.foodchem.2017.03.153. PMid:28490054.

Chen, J., Zhao, Y., Tao, X.-y., Zhang, M., \& Sun, A. (2015). Protective effect of blueberry anthocyanins in a CCL4-induced liver cell model. Lebensmittel-Wissenschaft + Technologie, 60(2), 1105-1112. http:// dx.doi.org/10.1016/j.lwt.2014.10.010.

Chen, L., Xin, X., Feng, H., Li, S., Cao, Q., Wang, X., \& Vriesekoop, F. (2020). Isolation and identification of anthocyanin component in the fruits of Acanthopanax sessiliflorus (Rupr. \& Maxim.) seem. by means of high speed counter current chromatography and evaluation of its antioxidant activity. Molecules, 25(8), 1781. http://dx.doi. org/10.3390/molecules25081781. PMid:32295006.

Chen, S., Zeng, Z., Hu, N., Bai, B., Wang, H., \& Suo, Y. (2018). Simultaneous optimization of the ultrasound-assisted extraction for phenolic compounds content and antioxidant activity of Lycium ruthenicum Murr. fruit using response surface methodology. Food 
Chemistry, 242, 1-8. http://dx.doi.org/10.1016/j.foodchem.2017.08.105. PMid:29037664.

Curi, P. N., Almeida, A. B., Tavares, B. S., Nunes, C. A., Pio, R., Pasqual, M., \& Souza, V. R. (2017). Optimization of tropical fruit juice based on sensory and nutritional characteristics. Food Science and Technology, 37(2), 308-314. http://dx.doi.org/10.1590/1678-457x.24716.

Espín, J. C., Soler-Rivas, C., Wichers, H. J., \& Garcia-Viguera, C. (2000). Anthocyanin-based natural colorants: a new source of antiradical activity for foodstuff. Journal of Agricultural and Food Chemistry, 48(5), 1588-1592. http://dx.doi.org/10.1021/jf9911390. PMid:10820063.

Grobelna, A., Kalisz, S., \& Kieliszek, M. (2019). The effect of the addition of blue honeysuckle berry juice to apple juice on the selected quality characteristics, anthocyanin stability, and antioxidant properties. Biomolecules, 9(11), 744. http://dx.doi.org/10.3390/biom9110744. PMid:31744240.

Haddi, Z., Mabrouk, S., Bougrini, M., Tahri, K., Sghaier, K., Barhoumi, H., El Bari, N., Maaref, A., Jaffrezic-Renault, N., \& Bouchikhi, B. (2014). E-Nose and e-Tongue combination for improved recognition of fruit juice samples. Food Chemistry, 150, 246-253. http://dx.doi. org/10.1016/j.foodchem.2013.10.105. PMid:24360446.

Jiang, W. H., Li, W., Han, L. K., Liu, L. J., Zhang, Q. B., Zhang, S. J., Nikaido, T., \& Koike, K. (2006). Biologically active triterpenoid saponins from Acanthopanax senticosus. Journal of Natural Products, 69(11), 1577-1581. http://dx.doi.org/10.1021/np060195+. PMid:17125224.

Kim, D.-M., Bae, J.-S., Lee, D.-S., Lee, H., Joo, M. H., \& Yoo, S.-H. (2011). Positive effects of glycosylated anthocyanin isolated from an edible berry fruit (Acanthopanax sessiliflorum) on its antioxidant activity and color stability. Food Research International, 44(7), 2258-2263. http://dx.doi.org/10.1016/j.foodres.2011.01.021.

Laureati, M., Buratti, S., Bassoli, A., Borgonovo, G., \& Pagliarini, E. (2010). Discrimination and characterisation of three cultivars of Perilla frutescens by means of sensory descriptors and electronic nose and tongue analysis. Food Research International, 43(4), 959964. http://dx.doi.org/10.1016/j.foodres.2010.01.024.

Lee, K. W., Kim, Y. J., Kim, D.-O., Lee, H. J., \& Lee, C. Y. (2003). Major phenolics in apple and their contribution to the total antioxidant capacity. Journal of Agricultural and Food Chemistry, 51(22), 65166520. http://dx.doi.org/10.1021/jf034475w. PMid:14558772.
Lee, S., Kim, B.-K., Cho, S. H., \& Shin, K. H. (2002). Phytochemical constituents from the fruits of Acanthopanax sessiliflorus. Archives of Pharmacal Research, 25(3), 280-284. http://dx.doi.org/10.1007/ BF02976626. PMid:12135097.

Liu, F., Zhang, X., Zhao, L., Wang, Y., \& Liao, X. (2016). Potential of high-pressure processing and high-temperature/short-time thermal processing on microbial, physicochemical and sensory assurance of clear cucumber juice. Innovative Food Science \& Emerging Technologies, 34, 51-58. http://dx.doi.org/10.1016/j.ifset.2015.12.030.

Mullen, W., Lean, M. E. J., \& Crozier, A. (2002). Rapid characterization of anthocyanins in red raspberry fruit by high-performance liquid chromatography coupled to single quadrupole mass spectrometry. Journal of Chromatography A, 966(1-2), 63-70. http://dx.doi. org/10.1016/S0021-9673(02)00699-4. PMid:12214705.

Nascimento, R., Tavares, P., Meireles, S., Anjos, E., Andrade, R., Machado, B., Souza, A. L. C., \& Mamede, M. E. O. (2020). Study on the sensory acceptance and check all that apply of mixed juices in distinct Brazilian regions. Food Science and Technology, 40(Suppl. 2), 708-717. http://dx.doi.org/10.1590/fst.37619.

Paredes-López, O., Cervantes-Ceja, M. L., Vigna-Pérez, M., \& Hernández-Pérez, T. (2010). Berries: improving human health and healthy aging, and promoting quality life - a review. Plant Foods for Human Nutrition, 65(3), 299-308. http://dx.doi.org/10.1007/ s11130-010-0177-1. PMid:20645129.

Sanoner, P., Guyot, S., Marnet, N., Molle, D., \& Drilleau, J. P. (1999). Polyphenol profiles of French cider apple varieties (Malus domestica sp.). Journal of Agricultural and Food Chemistry, 47(12), 4847-4853. http://dx.doi.org/10.1021/jf990563y. PMid:10606541.

Singleton, V., \& Rossi, J. (1965). Colorimetry of total phenolics with phosphomolybdic-phosphotungstic acid reagents. American Journal of Enology and Viticulture, 16(3), 144-158.

Vázquez-Araujo, L., Chambers, E. 4th, Adhikari, K., \& CarbonellBarrachina, A. A. (2010). Sensory and physicochemical characterization of juices made with pomegranate and blueberries, blackberries, or raspberries. Journal of Food Science, 75(7), S398-S404. http://dx.doi. org/10.1111/j.1750-3841.2010.01779.x. PMid:21535574.

Yang, C., An, Q., Xiong, Z., Song, Y., Yu, K., \& Li, F. (2009). Triterpenes from Acanthopanax sessiliflorus fruits and their antiplatelet aggregation activities. Planta Medica, 75(6), 656-659. http://dx.doi. org/10.1055/s-0029-1185330. PMid:19263344. 